\title{
Downscaling the climate change for oceans around Australia
}

\author{
M. A. Chamberlain ${ }^{1}$, C. Sun ${ }^{2}$, R. J. Matear ${ }^{1}$, M. Feng ${ }^{2}$, and S. J. Phipps ${ }^{3,4}$ \\ ${ }^{1}$ CSIRO Marine and Atmospheric Research, Castray Esplanade, Hobart TAS 7000, Australia \\ ${ }^{2}$ CSIRO Marine and Atmospheric Research, Floreat WA 6014, Australia \\ ${ }^{3}$ Climate Change Research Centre, University of New South Wales, Sydney, NSW 2052, Australia \\ ${ }^{4}$ ARC Centre of Excellence for Climate System Science, University of New South Wales, Sydney, NSW 2052, Australia \\ Correspondence to: M. A. Chamberlain (matthew.chamberlain@csiro.au)
}

Received: 17 January 2012 - Published in Geosci. Model Dev. Discuss.: 17 February 2012

Revised: 10 August 2012 - Accepted: 22 August 2012 - Published: 21 September 2012

\begin{abstract}
At present, global climate models used to project changes in climate poorly resolve mesoscale ocean features such as boundary currents and eddies. These missing features may be important to realistically project the marine impacts of climate change. Here we present a framework for dynamically downscaling coarse climate change projections utilising a near-global ocean model that resolves these features in the Australasian region, with coarser resolution elsewhere.

A time-slice projection for a 2060s ocean was obtained by adding climate change anomalies to initial conditions and surface fluxes of a near-global eddy-resolving ocean model. Climate change anomalies are derived from the differences between present and projected climates from a coarse global climate model. These anomalies are added to observed fields, thereby reducing the effect of model bias from the climate model.

The downscaling model used here is ocean-only and does not include the effects that changes in the ocean state will have on the atmosphere and air-sea fluxes. We use restoring of the sea surface temperature and salinity to approximate real-ocean feedback on heat flux and to keep the salinity stable. Extra experiments with different feedback parameterisations are run to test the sensitivity of the projection. Consistent spatial differences emerge in sea surface temperature, salinity, stratification and transport between the downscaled projections and those of the climate model. Also, the spatial differences become established rapidly $(<3 \mathrm{yr})$, indicating the importance of mesoscale resolution. However, the differences in the magnitude of the difference between experiments show that feedback of the ocean onto the air-sea fluxes is still important in determining the state of the ocean in these projections.
\end{abstract}

Until such a time when it is feasible to regularly run a global climate model with eddy resolution, our framework for ocean climate change downscaling provides an attractive way to explore the response of mesoscale ocean features with climate change and their effect on the broader ocean.

\section{Introduction}

Global-scale Atmosphere-Ocean General Circulation Models (AOGCMs) are used extensively to project the response of climate to increasing concentrations of infrared-absorbing, or "greenhouse", gases in the atmosphere. However, due to the complexity of these models, at present they are formulated at relatively low horizontal resolution (e.g. $1^{\circ}$ or $100 \mathrm{~km}$ ). This enables AOGCMs to run relatively quickly and to project the climate evolution over decadal and centurial time scales for various future climate scenarios. While global AOGCMs are valuable for providing global- and basin-scale trends in future climate, they are not designed to resolve all of the important ocean features, such as mesoscale eddies and boundary currents. Marine life in Australian waters is sensitive to climate change (Poloczanska et al., 2007), and many of these potential climate change impacts are influenced by mesoscale features, which are poorly resolved by AOGCMs (Hartog et al., 2011; Stock et al., 2011; Hobday and Lough, 2011). Some marine impact methods are based on mesoscale features, such as eddy-kinetic energy (Dell et al., 2011), which are absent from AOGCMs.

In order to make fine-scale projections from coarse AOGCMs, various downscaling methods have been applied. Most downscaling methods can be classified as either 


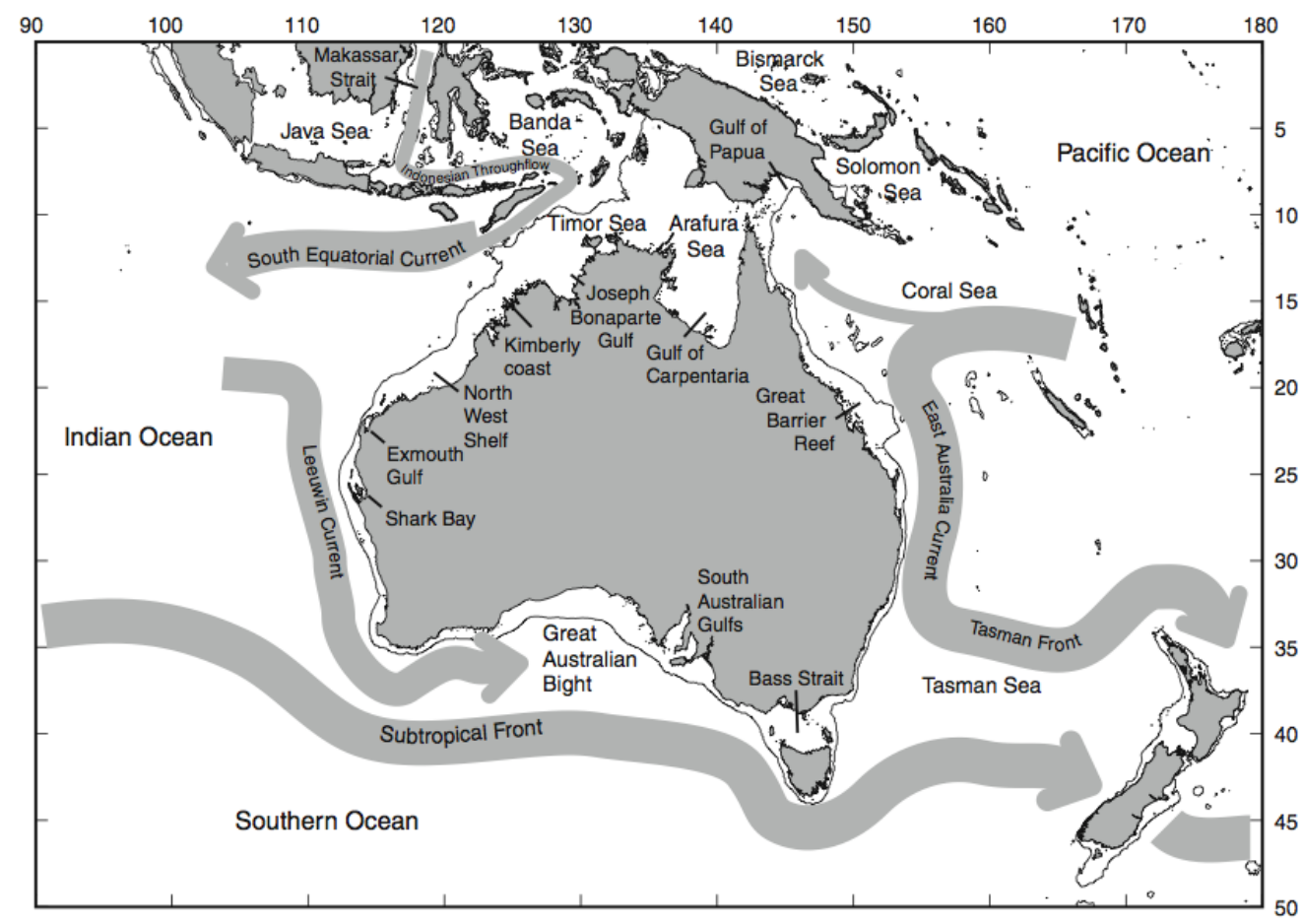

Fig. 1. Boundary currents around Australia, based on Poloczanska et al. (2007).

statistical or dynamical downscaling. Statistical downscaling requires defining relationships between local phenomena and large-scale features that can be found in coarse AOGCMs, using observational records (e.g. Heyen et al., 1996). Statistical downscaling has the advantage that it is quick to apply once relationships are defined, though it does assume that these relationships are invariant as the climate changes. Dynamical downscaling involves using a new circulation model that can resolve properties with higher resolution. The advantage of dynamical downscaling is that the models can explicitly resolve dynamics and linkages from the coarse to fine scales without assumptions. However, running models at higher resolution is computationally expensive and experiments are generally limited to time slices. We present here an approach that is based on a high-resolution ocean model that explicitly resolves features of interest, such as the boundary currents and eddy fields around Australia, to do dynamical ocean downscaling.

In the atmosphere, regional atmospheric models have a long history of being used to dynamically downscale global weather predictions to provide regional predictions (e.g. Lo et al., 2008; Laprise et al., 2008), and now these dynamical downscaling techniques are being modified and applied to make regional atmospheric climate change projections (e.g. Wang et al., 2004). However, there are few examples of dynamical downscaling of climate change projections for the ocean. Ådlandsvik (2008) nests a high-resolution model for the North Sea into an AOGCM; the surface forcing and the open boundary scheme use results from an AOGCM. Meier (2006) employs a two-step process to dynamically downscale the Baltic Sea. First a regional climate model is nested within an AOGCM, where the AOGCM drives the open boundaries. Second, the change in the atmospheric surface fields from the regional model are added to climatologies of reconstructed fields to drive the ocean model. Although the regional models provide an economical way to increase ocean resolution, the limited spatial extent of such models makes them unsuitable for investigating basin-scale phenomena like boundary currents.

This present study focuses on climate change in the oceans around the Australian region. Important boundary currents are found west and east of Australia (Fig. 1). In the west, the Leeuwin Current is a unique, poleward flowing eastern boundary current containing warm, low-salinity water sourced from the West Pacific via the Indonesian Throughflow (e.g. Cresswell and Golding, 1980). This current warms the Western Australian coast relative to other coasts at the same latitude (Feng et al., 2003). During the austral winter, the Leeuwin Current continues along the south coast of Australia, driven by winds and onshore Ekman flow as far as Tasmania (Ridgway and Condie, 2004). The Leeuwin Current, whose strength depends in part on El Niño/Southern Oscillation cycles of the tropical Pacific (Feng et al., 2003), is intimately linked to biological processes in the water off the west coast of Australia. It is associated with the shelf bloom of phytoplankton (Koslow et al., 2008; Moore et al., 
2007), the production of anti-cyclonic eddies with high phytoplankton biomass (Dietze et al., 2009; Moore et al., 2007), rock lobster biomass (Caputi et al., 2003, 2010) and other fish species (Hobday et al., 2008). In the east, the East Australia Current (EAC) is a strong western boundary current originating from the South Equatorial Current and flowing south along the east coast of Australia. While the main flow of the EAC separates from the coast at around $32^{\circ} \mathrm{S}$ and turns eastward between $33^{\circ} \mathrm{S}$ and $35^{\circ} \mathrm{S}$ (Ridgway and Dunn, 2003), some of the EAC continues south, influencing marine conditions as far south as Tasmania $\left(43^{\circ} \mathrm{S}\right)$. Mesoscale eddies driven by the EAC are prominent throughout this region. Dynamical studies show there is a good correlation between the strength of the EAC and the curl of the wind stress in the Pacific Ocean (Hill et al., 2008). EAC variability impacts the biodiversity and fish distributions along the east coast of Australia (Poloczanska et al., 2007).

This paper describes a framework to downscale AOGCM projections to provide regional projections of ocean climate change. We first present the models used for the downscaling, as well as methods used to generate the initial conditions and the atmospheric forcing fields required for the ocean downscaling model (ODM). We then discuss how we handle the feedback of the ocean state on the air-sea fluxes. Finally, we present several numerical experiments to investigate the feedback parameterisation on the climate change projection of the ODM. These experiments are used to demonstrate the robustness of ocean projections from the ODM. To gauge the influence of resolving mesoscale features of the future ocean state, we compare the response of the ODM simulation to the simulated AOGCM response. The approach used here to downscale the ocean in a future climate is generic and can be applied to any combination of AOGCM, climate scenario and ODM.

\section{Experiment setup}

\subsection{Methodology}

Ideally we would like an AOGCM that has an eddy-resolving ocean for future marine projections. Unfortunately, it is computationally prohibitive to pursue decadal to centurial time scale simulations with such a model and we are restricted to coarse AOGCMs for long simulations. We use a near-global ODM that is eddy-resolving in the Australian region and has the spatial scales that better resolve boundary currents (e.g. Leeuwin and East Australia Currents, Fig. 1), their source regions, and the eddies associated with these currents (Fig. 2). Unlike either of the ocean downscaling examples described above (Ådlandsvik, 2008; Meier, 2006), our ODM is nearglobal with no open boundaries. When a dynamic downscaling model is nested within a coarser model, much of the climate signal from the coarse model is passed through the open boundary conditions. However, since our ODM is global without nesting, our climate change signals from the AOGCM are contained within the initial conditions and forcing fields.

While AOGCMs are the best tools to assess climate scenarios on time scales of several decades and beyond, the climate states in these models are biased with respect to the observed climate. Like the Meier (2006) model, we reduce the effect of this model bias by using only the changes in climate from the AOGCM. On the other hand, ODMs are the best tools to study the upper ocean due to the explicit resolution of mesoscale features. However, ODMs are computationally expensive and are rarely run for more than a decade or so, which is too short to stabilise deep, slow ocean processes. Hence, the effect of climate change on the upper ocean is the focus of the projections in this study.

From an original spinup (Oke et al., 2008), we ran a control experiment (CTRL) with present-day climatology of surface fluxes, from which we simulate the current ocean state. Output from this CTRL experiment is used as a reference in the setup and analysis of the ODM projections.

The target of our time-slice projections is the decade of the 2060 s from the "A1b" medium emissions scenario (Nakicenovic et al., 2000). Climate signals from the AOGCM are then the change in ocean state and change in air-sea fluxes between the 1990s and 2060s, which are added to the observed ocean state and observed fluxes to produce initial conditions and forcing fields for the ODM experiments. These procedures are described in sections that follow.

ODM experiments here are ocean-only. Like other oceanonly experiments, we apply feedback from the ocean state to the surface forcing to: emulate realistic feedback in the observed ocean (Frankignoul et al., 1998), and avoid uncontrolled drift and instabilities (e.g. Zhang et al., 1993). Extra experiments with different feedback parameterisations are also presented to test the sensitivity of projections to feedback mechanisms. The ODM experiments are summarised in Table 1.

\subsection{Models}

\subsubsection{Global climate model}

In this study, the future climate projections from the CSIRO (Commonwealth Scientific and Industrial Research Organisation) Mk3.5 Global Climate Model (Gordon et al., 2010) are used to drive our climate ODM simulations. This AOGCM is an updated version of the CSIRO Mk3.0 (Gordon et al., 2002), which was a contribution to the Intergovernmental Panel on Climate Change Fourth Assessment Report (Solomon et al., 2007). Mk3.5 contains improvements in all components of the AOGCM from Mk3.0, in particular in the ocean eddy transfer coefficients and mixed layer scheme. The ocean resolution of the Mk3.5 AOGCM is $1^{\circ} \times 2^{\circ}$ with 31 vertical depth layers, 15 of which are in the upper $500 \mathrm{~m}$ (Fig. 2a). 
Table 1. Details of ODM experiments presented.

\begin{tabular}{|c|c|c|c|}
\hline $\begin{array}{l}\text { Experiment } \\
\text { name }\end{array}$ & $\begin{array}{l}\text { Initial } \\
\text { conditions } \\
\text { (details Sect. 2.3) }\end{array}$ & $\begin{array}{l}\text { Run } \\
\text { length } \\
\text { (yr) }\end{array}$ & $\begin{array}{l}\text { Surface fluxes } \\
\text { (details Sect. 2.4) }\end{array}$ \\
\hline Spinup & $\begin{array}{l}\text { World Ocean Atlas } \\
\text { (Levitus, 2002) }\end{array}$ & 16 & $\begin{array}{l}\text { Forced with reanalysis fluxes, } \\
\text { restored to observed } \mathrm{SST}^{*} \text { and } \mathrm{SSS}^{* *}\end{array}$ \\
\hline CTRL & End of year 16, Spinup & 26 & $\begin{array}{l}\text { Present-day climatology, } \\
\text { no feedback }\end{array}$ \\
\hline RELX & $\begin{array}{l}\text { End of year } 16, \text { Spinup } \\
\text { plus climate anomaly }\end{array}$ & 14 & $\begin{array}{l}\text { Projected climatology, feedback } \\
\text { on heat and freshwater with restoration } \\
\text { to SST and SSS (see Sect. } 2.5 \text { ) }\end{array}$ \\
\hline FREE & End of year 3, RELX & 3 & $\begin{array}{l}\text { Projected climatology, } \\
\text { no feedback }\end{array}$ \\
\hline STRS & End of year 3, RELX & 7 & $\begin{array}{l}\text { As for RELX with } \\
\text { stress feedback }\end{array}$ \\
\hline
\end{tabular}

(* Sea Surface Temperature; ${ }^{* *}$ Sea Surface Salinity)
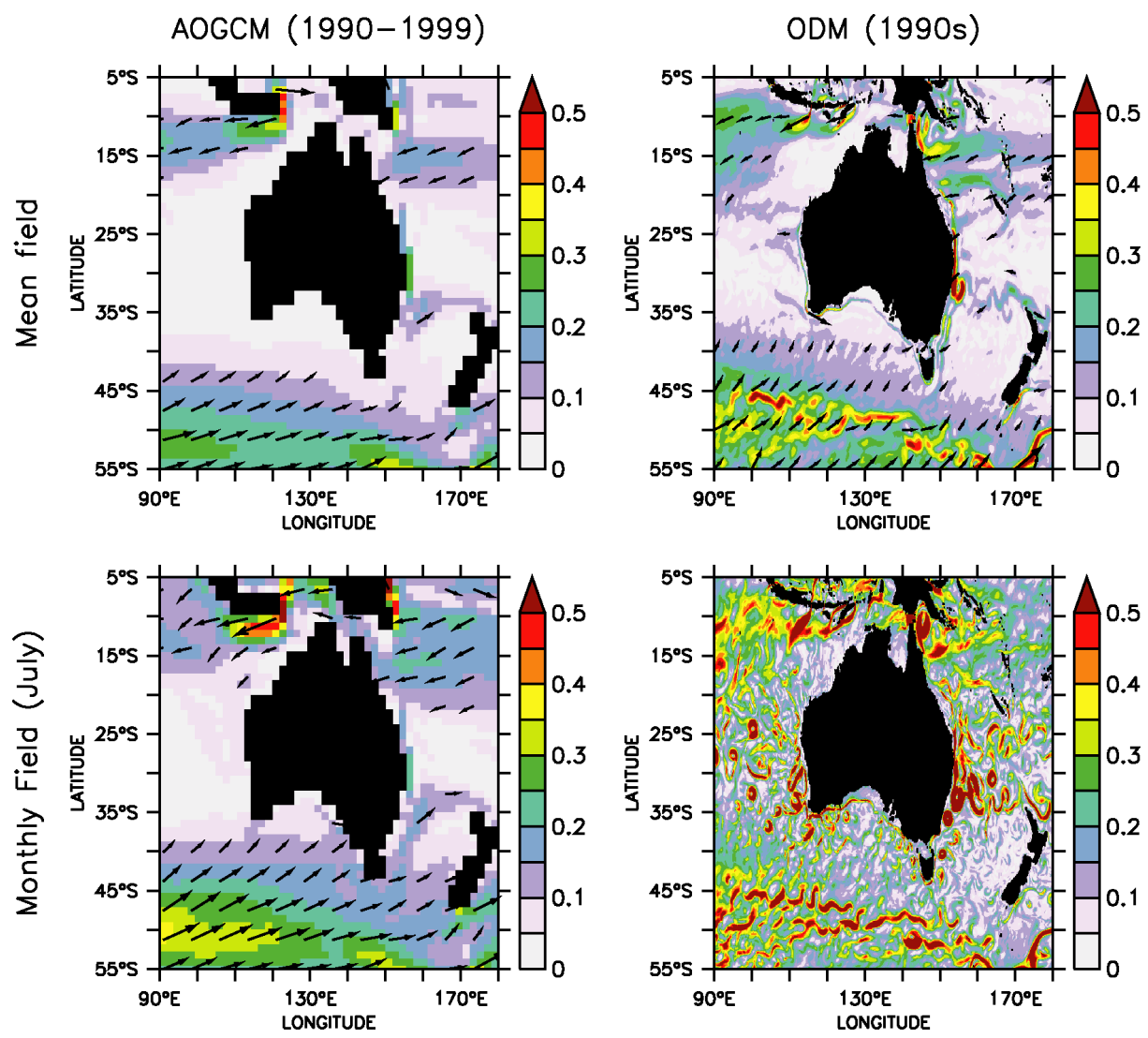

Fig. 2. Comparison of the surface currents from AOGCM (left column) and ODM (right). Shown are 10-year mean (top row) and monthly snapshots (bottom) of surface current velocity. Colours show the velocity magnitude (in $\mathrm{ms}^{-1}$ ), arrows indicate direction.

As part of the preparation for climate simulation, Mk3.5, like other AOGCMs, has been spun up so that the model drift is reduced to a negligible level. This is confirmed in AOGCM control experiments run in parallel to climate simulations, in which the climate models continue to simulate pre-industrial climate for centurial time scales. The stability in the climate state in these control experiments means that there is no need to correct for model drift in the Mk3.5 projections. 

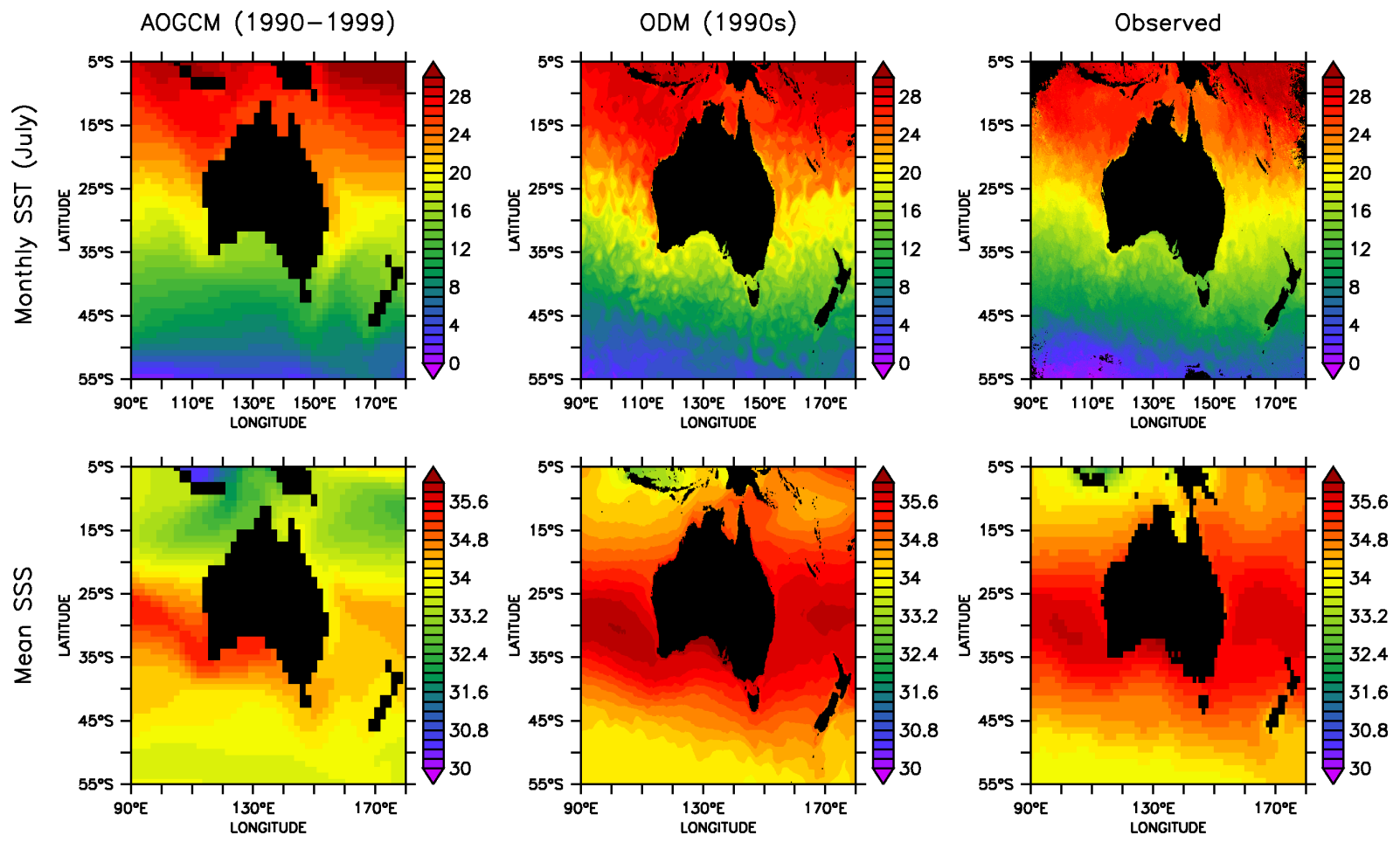

Fig. 3. Monthly snapshots of SST (top row, ${ }^{\circ} \mathrm{C}$ ) and mean sea surface salinities (bottom, practical salinity units - psu) for AOGCM, ODM and satellite AVHRR (Advanced Very High Resolution Radiometer) observations with the present climate.

\subsubsection{Ocean downscaling model}

We use the high-resolution Ocean Forecasting Australia Model (OFAM version 1) to dynamically downscale and explicitly resolve the effects of mesoscale currents and eddies on the projection of climate change. OFAM is based on the Modular Ocean Model, version 4.0 (MOM4, Griffies et al., 2004). OFAM is configured with variable spatial resolution on a near-global grid; the model does not include the Arctic Ocean. The vertical resolution in the upper $200 \mathrm{~m}$ of the water column is $10 \mathrm{~m}$. The model grid has variable horizontal spacing, which is eddy-resolving around Australia $\left(0.1^{\circ}\right.$ resolution in longitude and latitude between $90^{\circ}$ and $180^{\circ} \mathrm{E}$, and south of $16^{\circ} \mathrm{N}$ ), with coarser resolution outside this region, ultimately "telescoping" to $2^{\circ}$ resolution far from the region of interest. OFAM is used extensively to model dynamics in the Australian region (e.g. Schiller et al., 2009; Oke and Griffin, 2011). OFAM is the core of the Bluelink Ocean Data Assimilation System, which produces 7-day operational forecasts of the ocean state (Oke et al., 2005; Brassington et al., 2007) and has been used to produce a reanalysis of the ocean state around Australia over the last decade (Bluelink Reanalysis, Oke et al., 2008), as well as to explore the processes controlling spatial distribution of phytoplankton off both Western (Dietze et al., 2009) and Eastern (Mongin et al., 2011) Australia.
In experiments with present-day climate, our AOGCM and ODM generally show similarities in results at coarse scales, but have differences in details. The mean surface velocity fields from each model are broadly the same (top row, Fig. 2). However, while the monthly field from the AOGCM (bottom left) is very similar to the mean field, the monthly field from the ODM shows a lot of mesoscale variability that even masks the mean field. Schiller et al. (2009) demonstrate that transports of the main boundary current systems around Australia in the reanalysis experiment with this ODM are consistent with observations. Broadly speaking, the sea surface temperatures (SST, top row, Fig. 3) in the AOGCM and ODM are very similar to observed SST (top right). However, mesoscale dynamics within the ODM introduce variability in the SST similar to observations, which is missing in the SST simulated by the AOGCM. Mean sea surface salinity fields (SSS, bottom row, Fig. 3) show a clear bias in the AOGCM.

\subsection{Initial Conditions}

To prepare the ODM there was an initial spinup where the high-resolution ocean model was forced with reanalysis flux products (ERA-40, Uppala et al., 2005) and relaxed to observed surface temperature and salinity (Reynolds and Smith, 1994; Levitus, 2002); see Oke et al. (2008) for more details. The ODM was spun up for $16 \mathrm{yr}$, once with forcing fields from 1991 up to 2004 and then for a second "loop" of the forcing starting from 1993. The model at the end of 

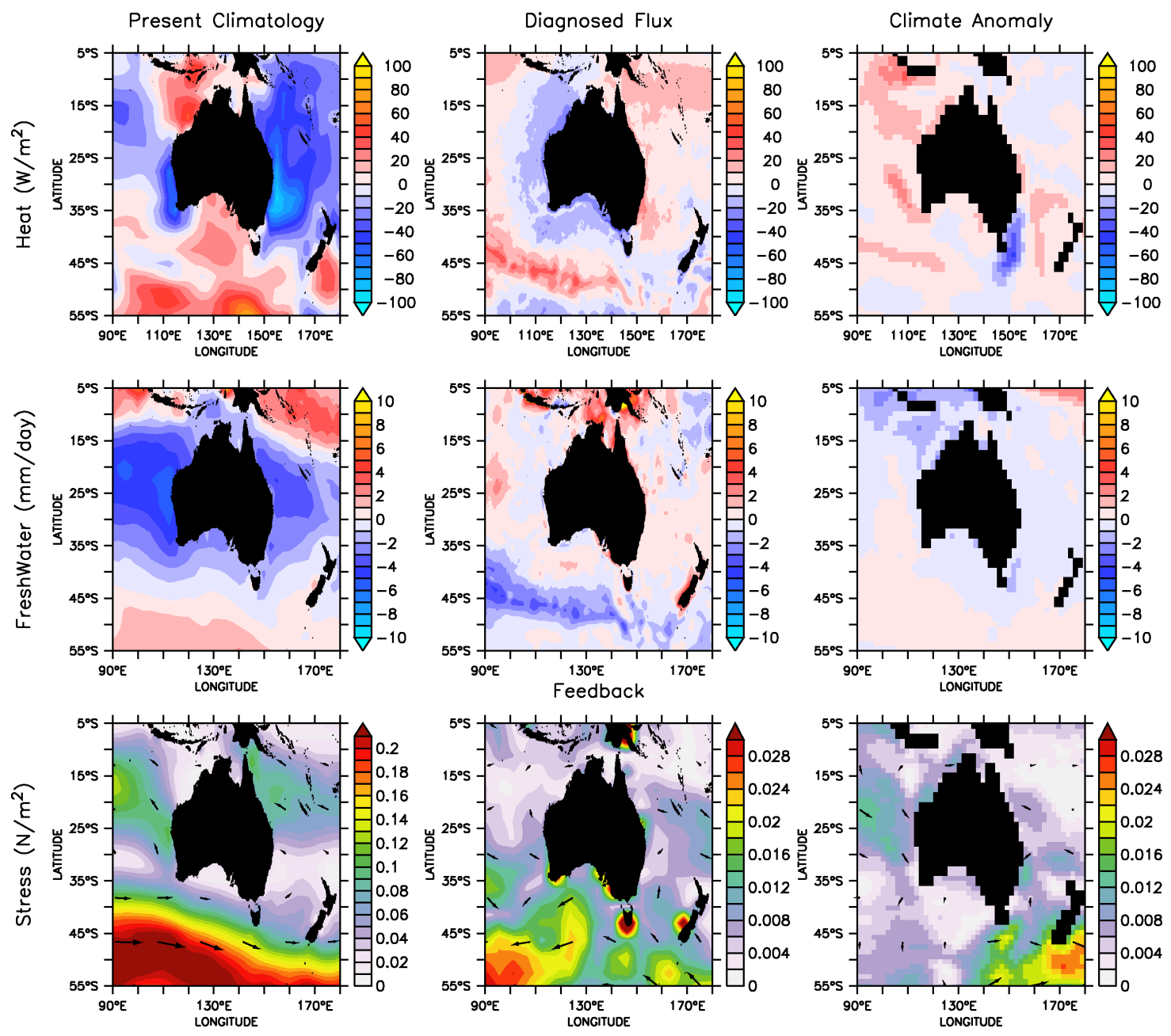

Fig. 4. Average forcing fields of heat (top), freshwater (middle) and surface stress (bottom) applied to ODM experiments. Forcings from present climatology are in the left column, climate anomalies in the right. The centre column shows the diagnosed fluxes for heat and freshwater based on the ODM spinup as the ocean was restored to observed surface fields, and the ocean feedback calculated to surface stress (see Sect. 2.5.2).

1994 on this second loop was used as the initial condition for a present-day ODM simulation (CTRL), since this was a time when the ocean was neither in a strong El Niño nor La Niña state.

Climate change anomaly fields in temperature and salinity from the AOGCM are added to the CTRL initial condition to construct initial conditions for the ODM climate projections. These anomalies are calculated and applied as global 3-D fields. The anomalies are shown in Sects. 3.2 and 3.3, where they are compared to changes in the ocean state with climate change in the ODM. The climate change anomaly fields are defined as the change from the decadal averages in the 1990s to the decadal averages in the 2060s. Climate change anomaly fields were used instead of the actual ocean state of the AOGCM in 2060 to remove the potential regional biases in the AOGCM-simulated ocean state (like SSS in Fig. 3). This approach assumes the AOGCM can correctly simulate changes in ocean state and atmospheric forcing between the two decades despite these biases.

Shorter projection experiments to test sensitivity to feedbacks were branched from the main projection. There is a large "shock" to the ocean state due to the addition of the AOGCM climate change anomaly, which would mask any differences, so we start these feedback experiments from an ocean state that has already run for $3 \mathrm{yr}$, after which most of the shock has dissipated. This approach made it easier to assess differences in the feedback experiments with less computer resources.

\subsection{Forcing fields}

The ODM control and projection experiments are all forced with constructed flux climatologies of heat, freshwater and momentum. Using climatologies removes interannual variability from the forcing and reduces the variability in the 
ocean state, which simplifies the comparison of results and so makes it easier to identify the response of the ocean to climate change. The climatology of forcing fields for CTRL was built from fluxes applied to the spinup experiment. The spinup was forced with observed surface fluxes (ERA-40, Uppala et al., 2005), and it was also restored to observed surface states, which allowed the model to diagnose the correction fluxes used to maintain observed ocean states of temperature and salinity. The heat, freshwater and momentum fluxes of the spinup from years 1993-2001 are averaged to produce a monthly climatology for present-day forcing. In building this climatology, diurnal variability is lost. Diurnal variability is added back with ERA-40 fluxes from 1995; 1995 is used since major ocean climate indices (e.g. El Niño, Indian Ocean Dipole) were neutral at this time. Diurnal variability in the fluxes is determined from the differences between the daily values and their monthly mean. Most components of heat flux can be treated as a single flux into the top ocean layer. However, shortwave radiation penetrates into the ocean, for which we use a monthly climatology computed from 1993-2001 ERA-40 shortwave flux for our CTRL and ODM projection experiments.

In the ODM climate projections, climate change anomalies from the AOGCM are added to these present-day fields. Like the anomaly applied to the initial conditions, climate anomalies are applied to the ODM forcing to reduce the effect of bias from the AOGCM. The approach of applying anomalies to forcing fields has been used before to keep models close to expected climatology (e.g. Kirtman et al., 2002). The climate change anomalies are calculated as the change in the monthly averaged fluxes between the decades of the 2060s and 1990s from the AOGCM. The ocean feedbacks parameterise how the ocean state in the ODM alters the fluxes, as detailed in the next section.

The following equations summarise the components used to construct ODM fluxes.

$$
\begin{aligned}
& \mathrm{HF}=\mathrm{SW}_{\text {present }}+\mathrm{LW}_{\text {present }}+\text { Sens }_{\text {present }} \\
& + \text { Lat }_{\text {present }}+\mathrm{HC}_{\text {present }}+\mathrm{H}^{\prime}+\mathrm{H}_{\text {feedback }}+\mathrm{H}_{\sigma} \\
& \mathrm{FW}=\mathrm{Prec}_{\text {present }}-\text { Evap }_{\text {present }}+\mathrm{FC}_{\text {present }} \\
& +\mathrm{FW}^{\prime}+\mathrm{FW}_{\text {feedback }}+\mathrm{FW}_{\sigma} \\
& \text { Stress }=\text { Stress } \\
& \text { present }
\end{aligned}
$$

The heat flux (HF, Eq. 1) is the sum of: present-day shortwave solar radiation (SW), longwave radiation (LW), sensible heat flux (Sens), latent heat due to evaporation (Lat), a correction term (HC) derived from the ODM spinup by relaxing the simulated SST with a time scale of 30 days to observations (Reynolds and Smith, 1994), the climate change heat flux anomaly from AOGCM experiments $\left(\mathrm{H}^{\prime}\right)$, a feedback term ( $\mathrm{H}_{\text {feedback }}$, discussed below), and diurnal variability $\left(\mathrm{H}_{\sigma}\right)$. The applied forcing from the present-day climate
(SW+LW+Lat+Sens) is the largest component of the heat forcing (up to $\sim 80 \mathrm{Wm}^{-2}$, top row, Fig. 4). $\mathrm{HC}$ and $\mathrm{H}^{\prime}$ are smaller components, each $\sim 20 \mathrm{Wm}^{-2}$.

The freshwater flux (FW, Eq. 2) is the sum of: precipitation (Prec), evaporation (Evap), a correction term (FC) derived from the ODM spinup by relaxing the simulated SSS with a time scale of 30 days to a monthly climatology (Levitus, 2002), the climate change freshwater flux anomaly from AOGCM experiments $\left(\mathrm{FW}^{\prime}\right)$, a feedback term $\left(\mathrm{FW}_{\text {feedback}}\right.$, discussed below), and diurnal variability $\left(\mathrm{FW}_{\sigma}\right)$. Present-day fluxes (Prec and Evap) are again the largest term in the constructed freshwater fluxes (middle row, Fig. 4), though this time the FC is larger than the $\mathrm{FW}^{\prime}$.

Stress (Eq. 3) gives the zonal and meridional components of momentum flux as the sum of: present-day stresses (Stress), climate change stress anomalies calculated from the AOGCM simulations (Stress'), a feedback term

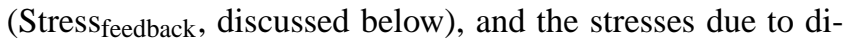
urnal variability $\left(\operatorname{Stress}_{\sigma}\right)$. The present-day forcing is much greater than the climate anomaly for surface stress (bottom left and bottom right of Fig. 4).

\subsection{Ocean feedback on air-sea forcing}

All ODM simulations in this study are done with an oceanonly model, which lacks the potential coupling of the ocean state with the atmospheric forcing. However, we do expect resolving mesoscale features to alter the future ocean state and for this to influence the fluxes of heat, freshwater and momentum between the atmosphere and ocean. We use the term "feedback" to denote the impact that the change in ocean state predicted by ODM may have on these fluxes. Ideally, one could do climate downscaling with a coupled model, but at this stage we have taken a simpler and more computationally efficient strategy of using an ocean-only model and relying on simple formulations of the feedback terms to account for the coupling. While our feedback parameterisations are simple, we try several different formulations to assess the sensitivity of the ODM climate change projection to the feedback parameterisation. The following section discusses how we parameterise the heat, freshwater and momentum flux feedbacks in the simulations performed. Table 1 summarises feedbacks used with a list of these simulations.

\subsubsection{Feedback of heat and freshwater}

To represent the ocean feedback on the air-sea heat and freshwater fluxes, we include additional heat and freshwater fluxes based on a simple restoring of SST and SSS to guide fields $\left(\mathrm{SST}_{\text {guide }}\right.$ and $\mathrm{SSS}_{\text {guide }}$ ). Guide fields are constructed by adding the monthly climate change anomalies from the AOGCM simulation to the monthly surface temperature and salinity climatologies from the control experiment. The form of the equations for restoring is a straightforward damping relationship: $\mathrm{H}_{\text {feedback }}=\alpha_{\mathrm{H}}\left(\mathrm{SSS}_{\mathrm{ODM}}-\right.$ 
$\left.\mathrm{SSS}_{\text {guide }}\right)$ and $\mathrm{FW}_{\text {feedback }}=\alpha_{\mathrm{FW}}\left(\mathrm{SSS}_{\mathrm{ODM}}-\mathrm{SSS}_{\text {guide }}\right)$. The time scale for restoring was 30 days for both SST and SSS, which gives feedback coefficients with this ODM of $\alpha_{H}=$ $-16 \mathrm{~W} \mathrm{~m}^{-2} \mathrm{~K}^{-1}$ and $\alpha_{F W}=+10 \mathrm{~mm} \mathrm{day}^{-1} \mathrm{psu}^{-1}$ (assuming a salinity of $35 \mathrm{psu})$.

There is a clear physical argument for linking the SST anomaly with heat flux, which is quantified in bulk flux formulas (Large, 2005). Heat loss via longwave radiation, evaporation/latent heat and sensible heat are all strong functions of temperature, in addition to other properties such as wind speed. This approach has been shown to approximate the feedback of the real ocean and air-sea fluxes by Frankignoul et al. (1998), who found an average observed feedback coefficient of $-20 \mathrm{~W} \mathrm{~m}^{-2} \mathrm{~K}^{-1}$ for the North Atlantic, which is comparable to our coefficient. Frankignoul et al. (1998) found that ideally the feedback coefficient would be a function of latitude and season as well. Here, however, we use the surface restoring capability of the model, which is constant and uniform everywhere.

It is less clear that SSS anomalies and freshwater fluxes are linked. SSS restoring is applied for two main reasons. Firstly, the freshwater fluxes that control the surface salinity are poorly defined for even the present ocean. Secondly, we wish to ensure that the upper ocean density does not undergo a dramatic transition within the ODM that would be induced by differences in advection and/or vertical mixing between the models. In general, simulations without feedback typically drift away from observed salinity fields and exhibit instabilities in the thermohaline circulation (e.g. Zhang et al., 1993; Weaver et al., 1993). In particular, ocean-only experiments with "mixed boundary conditions", i.e. with constrained temperature with either restoring or bulk formulas and unconstrained salinity, lead to oscillations in thermohaline circulation on time scales of decades and centuries, which we want to avoid. Cai and Godfrey (1995) find that loosening the constraints on SST to allow SST to feedback onto the circulation has a stabilising effect. There is also potential for coupling between the restoring freshwater flux with SST and the heat flux through latent heat (evaporation or condensation). However, for typical magnitudes of heat flux feedback, the equivalent freshwater flux is small relative to the applied freshwater feedback. For instance, the typical latent heat flux feedback of $5 \mathrm{~W} \mathrm{~m}^{-2}$ would equate to a freshwater flux of $0.17 \mathrm{~mm} \mathrm{day}^{-1}$, and this is an order of magnitude less than the typical freshwater flux feedback in our experiments.

Restoring to surface fields of temperature and salinity also has the effect of keeping the changes in the ODM projection looking like those of the AOGCM. If resolving mesoscale features had no impact on the projected climate change, then feedback terms would be zero. To quantify how the heat and freshwater feedback restrain the ODM-projected climate change, we do another experiment without this feedback (FREE).

\subsubsection{Feedback of wind stress}

To quantify how changes in the ocean state impact the atmospheric circulation, we conducted atmosphere-only simulations using the CSIRO Mk3L model (Phipps et al., 2011). The atmosphere component of this model is a reducedresolution version of the atmospheric model used in the Mk3.5 AOGCM. Two simulations were conducted to assess the impact of SST change on the wind stress field. Firstly, we used a climatology of the monthly SST fields from the Mk3.5 AOGCM decade of the 2060s. Secondly, we constructed a new SST climatology by adding the change in SST from the 1990s to 2060s found with the ODM (RELX experiment) to the Mk3.5 SST in the 1990s. Both simulations were run for $60 \mathrm{yr}$, and we used the average of the last $30 \mathrm{yr}$ to compute the differences in the monthly surface wind stress between the two simulations, which we call the wind stress feedback. The 30-yr averaged wind stress feedback (bottom centre, Fig. 4) was added to the wind stress used in the RELX and FREE experiments to assess the impact of wind stress feedback (experiment STRS, Table 1). The magnitude of the wind stress feedback is much less than the applied stress. However, the feedback term is comparable to the climate anomaly (bottom right, Fig. 4).

\section{Climate change projections}

In this section we use various ODM experiments (FREE, RELX and STRS from Table 1) to simulate the consequence of resolving mesoscale features in the Australian region on the projected ocean state in a future climate. Firstly, we present results from extended runs of the CTRL and RELX experiments to demonstrate the temporal stability of the ODM results.

To help discuss the results for both the AOGCM and ODM, we define "projected climate change" as the difference in ocean state from a single model between the 2060s and 1990s. For the AOGCM, change is calculated as the difference between decadal averages of the 2060s and 1990s. For the ODM, the change is calculated as the average of one or more years in the projection minus a decadal average from the CTRL experiment.

We also define "difference in climate change" as projected climate change (as defined above) from the ODM minus the projected climate change of the AOGCM. If the projected climate changes were the same in the ODM and AOGCM, the difference in climate change would be zero. In the following discussion, we focus on the difference in climate change by comparing annual or multi-year averages of four key fields: (1) SST, (2) SSS, (3) upper ocean currents, and (4) stratification. By identifying differences common to each experiment, results are less sensitive to the bias in any of the individual model setups.

In some figures, for consistency, we compare results from just one year from each experiment, since the FREE 
$\mathrm{SST}_{\text {avg }}(\operatorname{deg} \mathrm{C})$

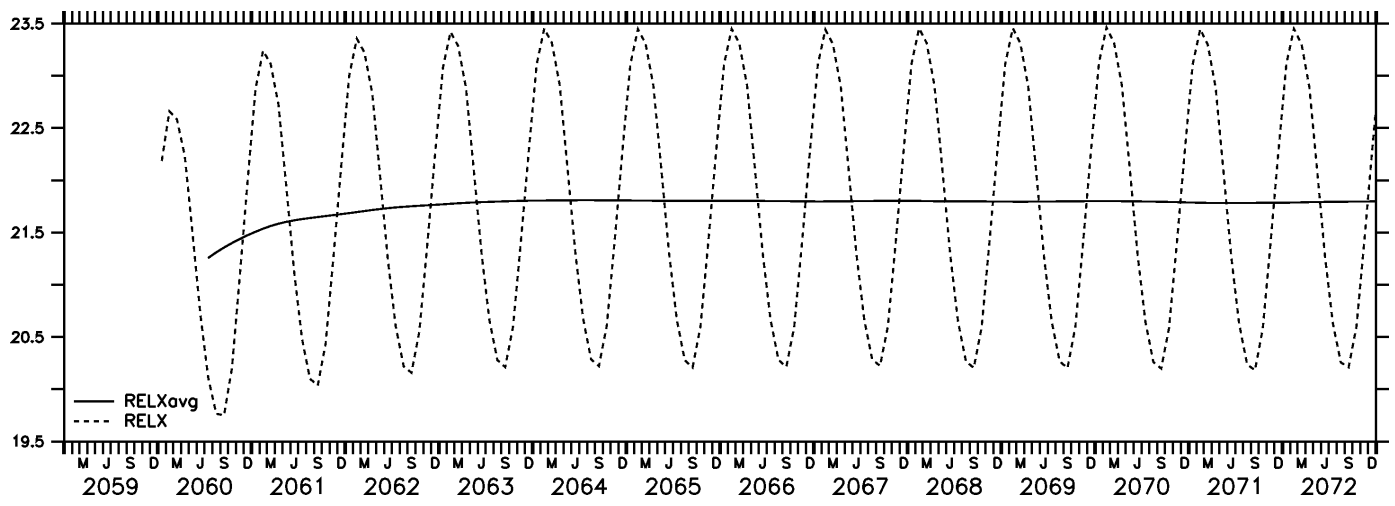

Fig. 5. Time series of monthly SST averaged over the region of interest for the RELX ODM projection. Also shown is the same SST smoothed with a 12-month filter.

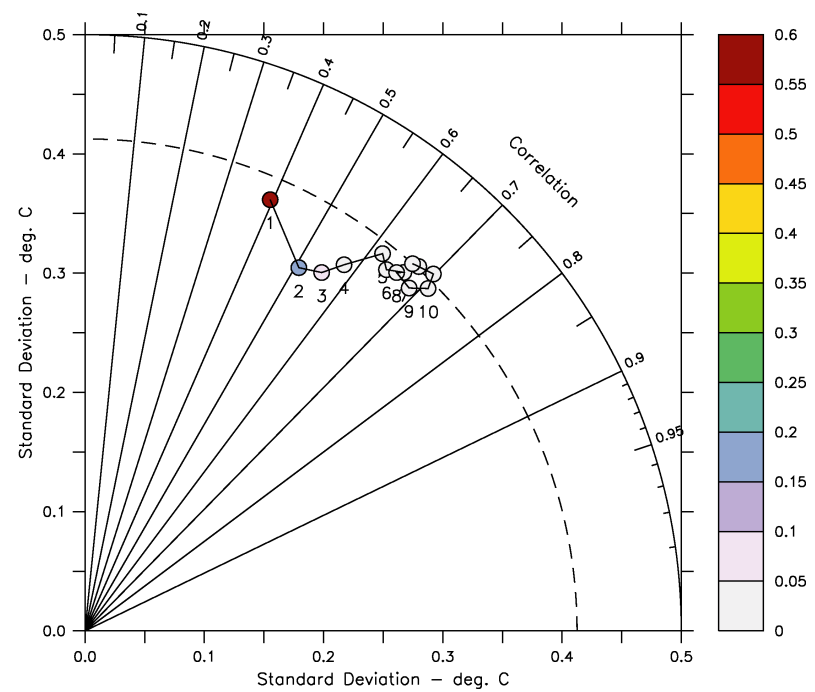

Fig. 6. Taylor diagram of the convergence of SST in the RELX experiment. The radial position is the standard deviation of the difference between the annual SST and the guide field for each year of the experiment (in ${ }^{\circ} \mathrm{C}$ ). The angular position gives the correlation of SST difference fields with the field of the following year, so point " 5 " is the correlation of SST from years 5 and 6 . A perfectly correlated (or anti-correlated) field would appear somewhere on the $x$-axis on the Taylor diagram, a completely uncorrelated field would be on the $y$-axis. The value of the difference in the average for the Australian region to the average of the final year $\left({ }^{\circ} \mathrm{C}\right)$ is represented by the colour of each point.

experiment only ran for $3 \mathrm{yr}$ from when it branched from RELX. In these figures, the third year from the common branch point is shown for each experiment. Since the ODM resolves mesoscale dynamics, there is considerable variability in the annual averages at the mesoscale. However, we restrict ourselves to comparisons of broader-scale features, which are more consistent. Alternatively, variability at a sin- gle location can be reduced by taking the average of the projected state over several years.

\subsection{Temporal stability in ODM output}

Extended integrations of the experiments CTRL and RELX are used to assess temporal stability of the ODM projections. Of particular interest is the run time required for the ocean state in the ODM climate projection to dissipate any shock in the initial conditions and adjust to the new forcing conditions.

Given the ocean's inertia and the time it takes the ocean to respond to a change in atmospheric forcing, the ODM projection is not expected to be in a steady state. To initially assess the temporal evolution of the experiment, both the seasonally resolved and annual averaged SSTs around Australia are shown in Fig. 5 for the RELX projection. The trend from RELX has stabilised from the shock of the climate anomaly applied to the initial condition after $3 \mathrm{yr}$.

Average SST is stable in Fig. 5; however, there is no spatial information in this average. We assess the temporal stability of the spatial pattern in the difference of SST change between the ODM and AOGCM, and compare this difference field between subsequent years. On a Taylor diagram we display the standard deviation of each annual difference and the correlation of difference fields between sequential years (Fig. 6). The correlation increases significantly after the first few years as the pattern in the difference in SST change becomes established. Due to eddy variability in the ODM, we do not expect any two years to look identical, but by the fifth year the changes in SST correlations converge to 0.6 to 0.7 , and a standard deviation in the SST difference field is $\sim 0.4^{\circ} \mathrm{C}$.

To gauge the stability of the ocean circulation in the Australian region, we examine a time series of volume transport through a section of the EAC at $28^{\circ} \mathrm{S}$ and $153-157^{\circ} \mathrm{E}$ (Fig. 7). We focus on the EAC because it is Australia's 


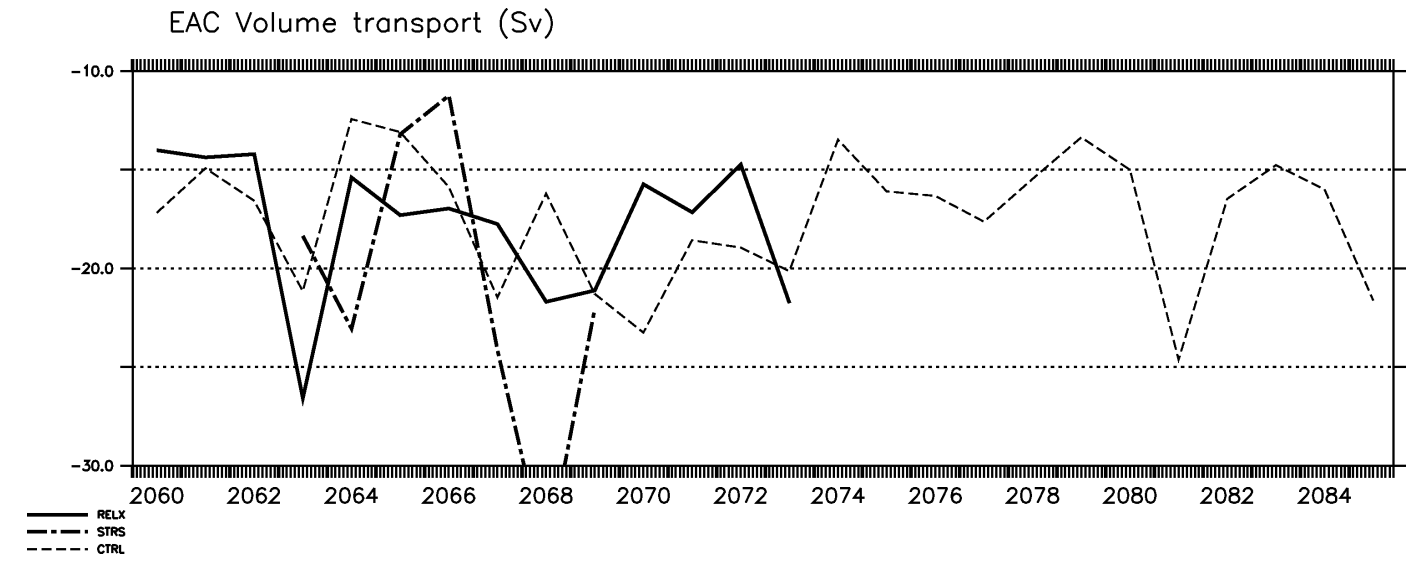

Fig. 7. EAC volume transport $\left(1 \mathrm{~Sv}=10^{6} \mathrm{~m}^{3} \mathrm{~s}^{-1}\right)$ in ODM experiments through a section at $28^{\circ} \mathrm{S}$. Volume transports shown are annual averages of the integrated north-south flow through $153-157^{\circ} \mathrm{E}$ and $0-600 \mathrm{~m}$ depth; values are negative since the flow is to the south. Transport in CTRL is a thin dashed line, which is shifted in time, RELX is a solid line, STRS is a dash-dot line. Note that all these experiments use repeat-year forcing, so the year values only indicate the year into each simulation, not the calendar year.

strongest boundary current, and the change in wind stress in the Eastern Pacific in our future climate change simulations may generate slowly propagating Rossby waves that alter the EAC transport (Hill et al., 2008). The CTRL and RELX experiments do not appear to have any discernible drift or trend in EAC transport. All ODM climate change simulations have similar EAC transport, with large interannual variability due largely to the eddy variability still influencing the section used to calculate the transport. Studies that focus on these transports in models use multi-year averages (e.g. Schiller et al., 2009; Sun et al., 2012), though in this work our intention is to demonstrate there is no significant drift in the model and that results are broadly similar between experiments with different setups.

We find that the shock from the addition of the climate anomaly to the ODM ocean state is gone from the upper ocean after the first few years. After this, we find the broadscale features are stable and are independent of which year is shown. We branch the experiments to assess the impact of different feedback (FREE and STRS) from $3 \mathrm{yr}$ into the RELX projection to avoid this shock. Also, $3 \mathrm{yr}$ allows the upper ocean in these extra experiments to respond to the different feedback parameterisation.

\subsection{SST}

The projected climate change in SST in both the AOGCM and the ODM shows a warming of generally 1 to $2{ }^{\circ} \mathrm{C}$ in SST over the Australian region (Fig. 8). Both models show somewhat less warming in regions around Indonesia and in the Southern Ocean, though the Southern Ocean in the ODM also has regions of enhanced warming. There is also less warming around New Zealand in both models. Note that the projected SST change from the AOGCM is the same as the surface field of the anomaly applied to the initial condi- tions used to set up the ODM projection (Sect. 2.3). While there are similarities between the projected changes from each model, as described above, there are also significant differences showing where the ODM has modified the climate anomaly imposed on the initial condition. The projected change in SST according to the AOGCM shows a strong warming feature off the coast of Tasmania $\left(150^{\circ} \mathrm{E}, 40^{\circ} \mathrm{S}\right)$, whereas in the ODM this warming is found in the central Tasman Sea. The difference in the projected change in SST between the models (right, Fig. 8) also highlights other differences in the warming pattern found with the ODM, such as greater warming in the Indian Ocean and near Indonesia, and reduced warming in the Great Australian Bight.

In order to confirm that the features found in the projected changes and the differences in projected change are not sensitive to the setup of the experiments, we compare results from ODM experiments with different parameterisations of air-sea feedbacks (Fig. 9). For consistency, the average of the third year from the common branch point is shown for each experiment (which is the sixth year from the projected initial condition), since the FREE experiment was not integrated long enough for a multi-year average. The difference in climate change of annual SSTs exhibits a similar spatial structure for each experiment (centre column, Fig. 9). The amplitude of the difference in climate change for SST, as measured by the standard deviation of these differences over the region shown in Fig. 9, is significantly larger for FREE $\left(0.69^{\circ} \mathrm{C}\right)$ than for experiments with SST restoring (i.e. RELX $0.40^{\circ} \mathrm{C}$ and STRS $0.43^{\circ} \mathrm{C}$ ). However, despite the different amplitudes, SST differences are well correlated spatially between all experiments: $R=0.65$ between FREE and RELX, and, $R=0.63$ between STRS and RELX. For comparison, typical $R$ values found in SST differences between different years of the same experiment are between 0.6 and 0.7. 

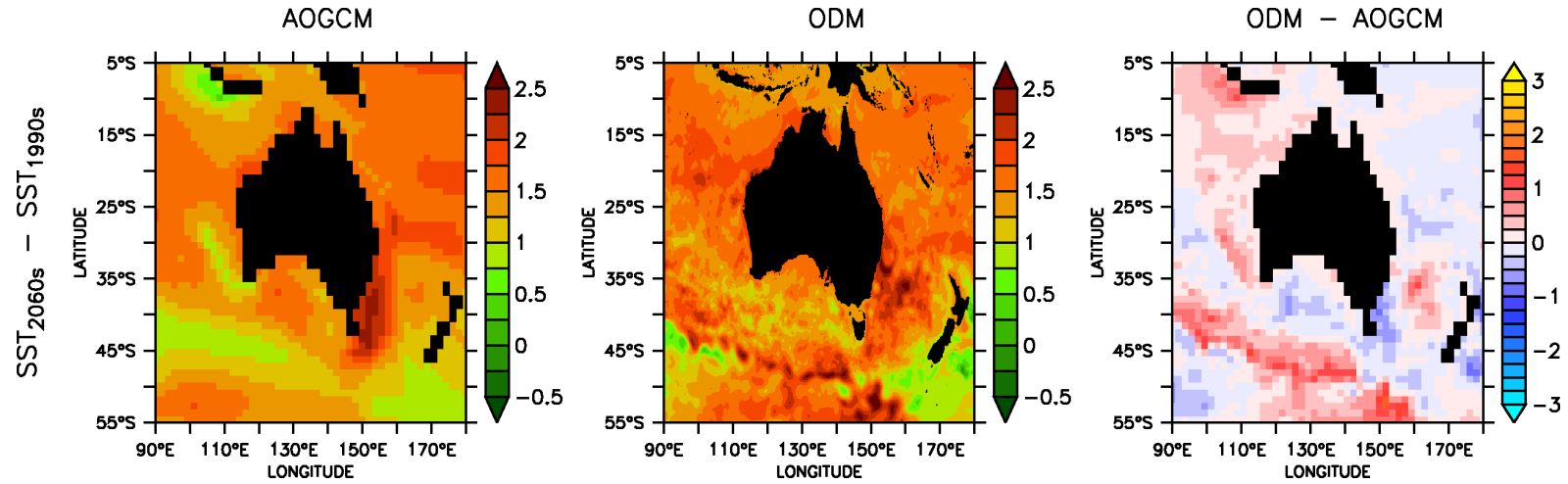

Fig. 8. 10-yr averages of the projected climate change in SST (in ${ }^{\circ} \mathrm{C}$ ) from the AOGCM, RELX-ODM, and their difference.
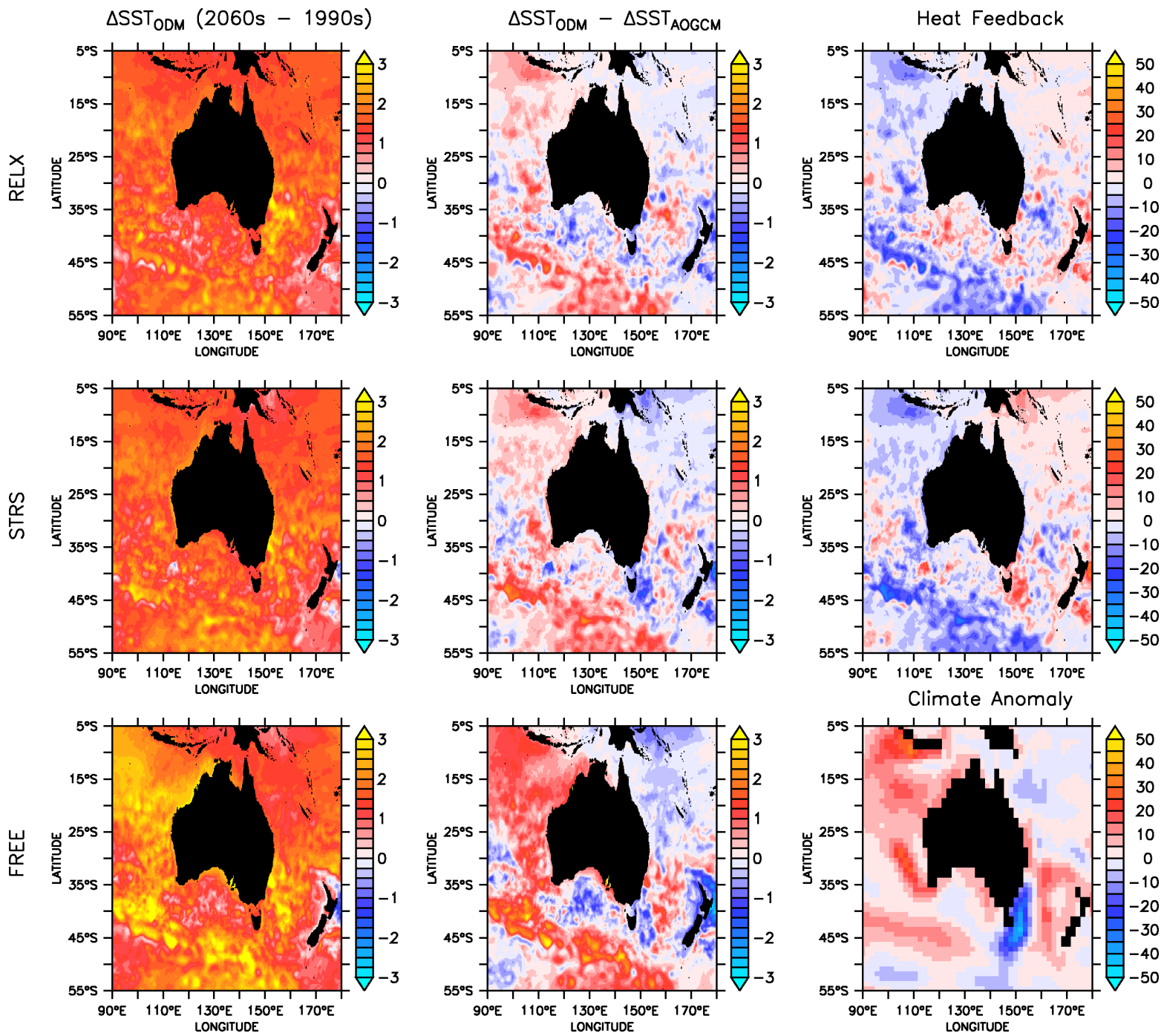

Fig. 9. Annual averages of: projected climate change in SST from the ODM (left column, in ${ }^{\circ} \mathrm{C}$ ), differences in climate change for SST (centre, ${ }^{\circ} \mathrm{C}$ ), and heat flux feedback (right, $\mathrm{W} \mathrm{m}^{-2}$ ). For comparison, the average climate change heat flux anomaly is shown in the bottom right panel. The RELX experiment is shown along the top, STRS is in the middle, and FREE is at the bottom. 

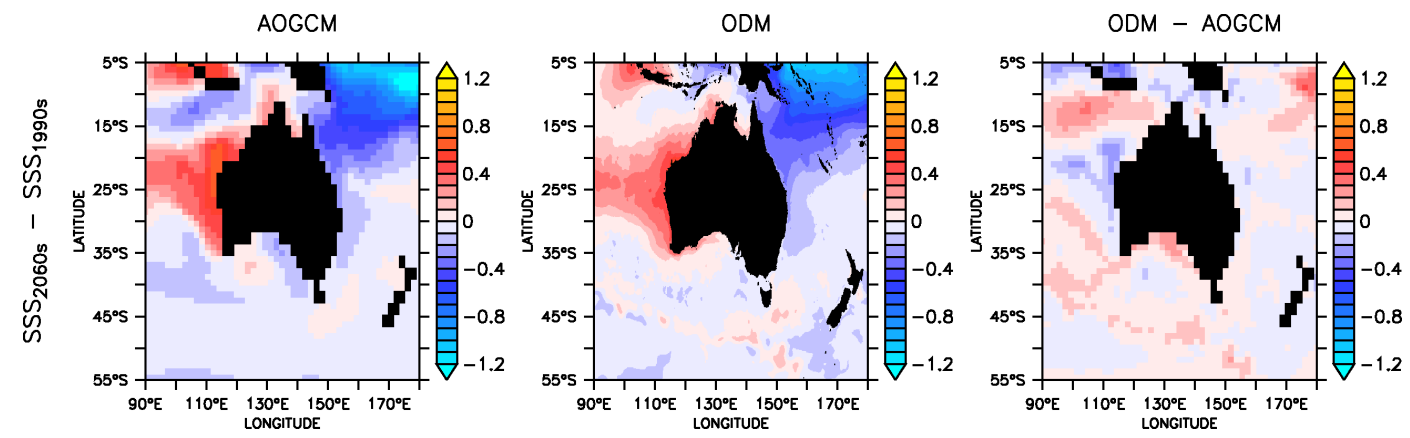

Fig. 10. 10-yr averages of the projected climate change in SSS (psu) for the AOGCM, ODM, and their difference.
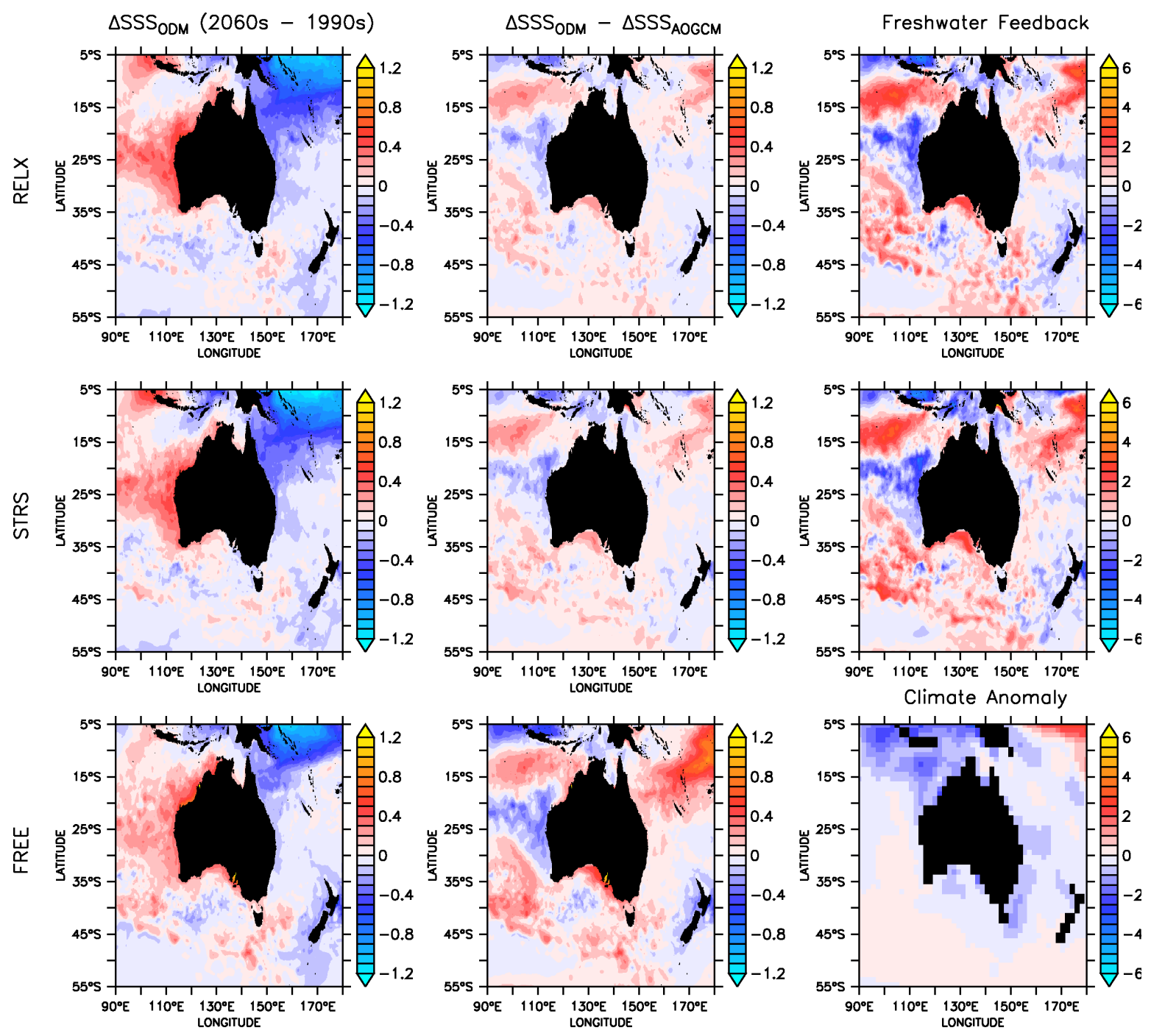

Fig. 11. Annual averages of: projected climate change in SSS from the ODM (left column, in psu), differences in climate change for SSS (centre, psu), and freshwater flux feedback (right, $\mathrm{mm} \mathrm{day}^{-1}$ ). For comparison, the average climate change freshwater flux anomaly is shown in the bottom right panel. The RELX experiment is shown along the top, STRS is in the middle, and FREE is at the bottom.

The consistent spatial pattern in different experiments indicates the mechanism driving the SST difference is insensitive to the feedback parameterisation. For instance, RELX heat flux feedback ranges from -25 to $+25 \mathrm{~W} \mathrm{~m}^{-2}$ over the region (right column, Fig. 9), yet the difference in SST response (centre column) retains the prominent warmer and 

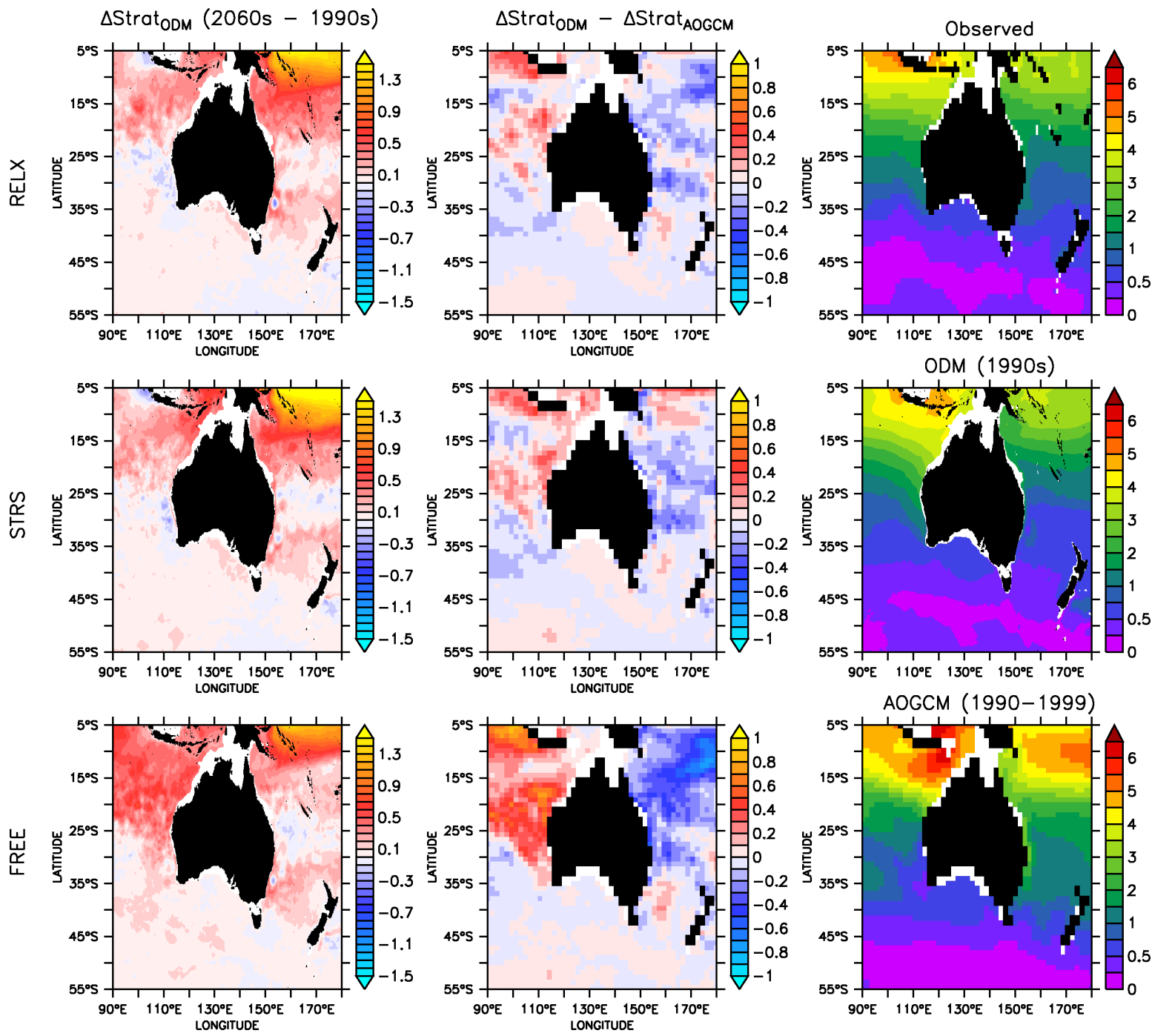

Fig. 12. Annual averages of: projected climate change in stratification from the ODM (left column, in $\mathrm{kg} \mathrm{m}^{-3}$ ), and differences in climate change for stratification (centre, $\mathrm{kg} \mathrm{m}^{-3}$ ). In these columns, the RELX experiment is shown along the top, STRS is in the middle, and FREE is at the bottom. The right column shows stratification for the 1990s in the ODM and AOGCM compared to observations (Levitus, 2002). Stratification is shown here as the difference in density of water at a depth of $200 \mathrm{~m}$ and at the surface.

cooler regions of the FREE experiment, in which the heat flux feedback is zero. The wind stress feedback (STRS) does not significantly affect the spatial structure of the difference. But the STRS experiment does show a larger decrease in warming in the Tasman and Coral Seas than the RELX experiment, which is more consistent with the FREE experiment. However, feedback parameterisation does influence the magnitude of the difference pattern. While the feedback parameterisations here are relatively simple and could be improved in the future, these experiments indicate that the pattern of the difference would be likely to be the same.

Where these spatial differences are independent of the surface fluxes implies that they are driven by ODM mesoscale resolution, such as differences in the transport and mixing. Since the ODM is eddy-resolving, it can calculate eddy trans- port and mixing explicitly rather than relying on parameterisations. Also, the resolution of cyclonic and anti-cyclonic eddies allows for a better representation of vertical movement and mixing. It is beyond the scope of this work to attribute the exact role of these processes to the various features identified in the differences found in the projected changes; our objective at this time is to demonstrate that these features are robust with respect to surface fluxes.

\subsection{Salinity}

The projected climate SSS changes of the AOGCM and all the ODM projections (Figs. 10 and 11) are more consistent than they were for SST. The projected change from the AOGCM was the anomaly added to the ODM initial 

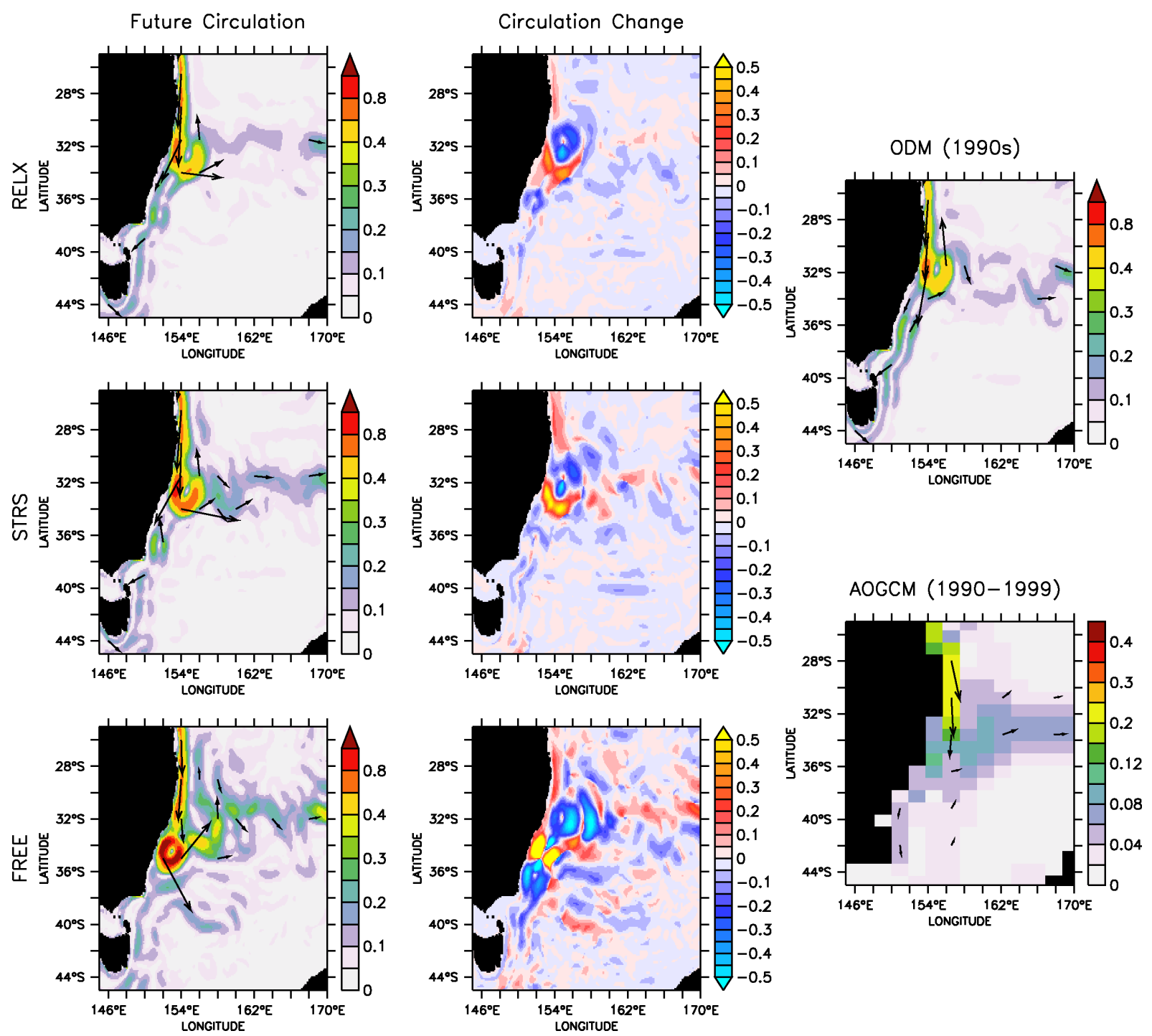

Fig. 13. The average current over the top $250 \mathrm{~m}$, in $\mathrm{m} \mathrm{s}^{-1}$, is used here as a proxy for transport; colours indicate magnitudes, arrows show direction. Multi-year averages are shown of: transport in the upper ocean from the ODM (left column), and projected climate change in transport (centre). Transport changes are calculated in the direction of the present-day transport. The RELX experiment is shown along the top (average of $10 \mathrm{yr})$, STRS is in the middle (5 yr), and FREE is at the bottom (1 yr). For reference, the transport fields for the $1990 \mathrm{~s}$ in the ODM and AOGCM are shown in the right column.

condition, so it appears that this initial condition is a significant component in the projected change found from the ODM for salinity. The projected climate changes in SSS show a prominent decrease in salinity in the Coral Sea and Western Equatorial Pacific, and a prominent increase in salinity in the mid-latitude Indian Ocean off Western Australia and around the island of Java (left column, Fig. 11). The difference in climate change annual SSSs (ODM climate change - AOGCM climate change) shows freshening in the midlatitudes west of Australia, and saltier conditions in the tropics at $\sim 10-15^{\circ} \mathrm{S}$ and in most of the Southern Ocean (middle column, Fig. 11).
As found with SST, with the freshwater feedback (restoring to SSS guide fields), the magnitude of the SSS difference declined. The standard deviation of the SSS difference in FREE is 0.19 psu, compared to 0.10 and 0.11 psu for RELX and STRS, respectively. However, the spatial pattern evident in the FREE experiment remained in the RELX and STRS experiments, e.g. the spatial correlation coefficient $(R)$ between FREE and RELX is 0.77 . As for SST and heat fluxes in the previous section, the consistent pattern in experiments with respect to different feedback indicates that the difference produced by mesoscale resolution is robust. Note that in experiments with SSS restoring, the freshwater flux feedback is greater than the climate anomaly flux (bottom right panel, 
Fig. 11). This large freshwater flux feedback still does not modify the spatial pattern of the difference in SSS response, even though it certainly affects the size of the difference.

\subsection{Upper ocean vertical stratification}

To assess projected climate changes in the upper ocean's vertical stratification, we calculate the annual averaged difference in water density between a depth of $200 \mathrm{~m}$ and the surface (Behrenfeld et al., 2006). The ODM climate change projections show increased stratification almost everywhere in the Australian region (left column, Fig. 12). The largest increases in stratification are equatorward of $20^{\circ} \mathrm{S}$. In the experiments with heat and freshwater feedbacks (RELX and STRS), the greatest increases in stratification occur in the tropical Pacific. The FREE experiment shows large increases in stratification occur in the Indian Ocean, too.

For reference, upper ocean vertical stratification of the present day is shown for the ODM and AOGCM (right column, Fig. 12). The ODM stratification is similar to the observed stratification (top right, Fig. 12) (Levitus, 2002). In contrast, the AOGCM tends to overestimate the vertical stratification, particularly north of $15^{\circ} \mathrm{S}$.

Differences in the change in upper ocean stratification in all experiments (centre column, Fig. 12) show a similar pattern of reduced stratification change in the Pacific and increased stratification change in the mid-latitude Indian Ocean relative to the AOGCM-projected changes. As for SST and SSS, the magnitudes of differences in stratification changes are greater in the FREE experiment than RELX or STRS. These stratification difference patterns are similar to the differences in SSS change. In the Indian Ocean, regions of increased stratification correspond to regions that are fresher, while in the Pacific Ocean, regions of decreased stratification correspond to regions that are saltier (Fig. 11). The correlation coefficient $(R)$ of the stratification difference with the SSS difference is -0.65 for the FREE experiment, and -0.49 for RELX. It appears that differences in vertical stratification are closely related to differences in SSS.

\subsection{Upper ocean transport}

To assess changes in the upper ocean circulation, we calculate the mean velocity averaged over the upper $250 \mathrm{~m}$ from each experiment (left column, Fig. 13), which we use here as a proxy for transport. In Fig. 13, just the Tasman Sea region is shown, which includes the prominent EAC boundary current, in order to demonstrate the consistency between experiments of features that are indiscernable at larger scales. To assess the various ODM simulations of climate change, we focus on how the transport differs between our three projection experiments rather than on making a comparison to the coarse-resolution AOGCM, as it is simply unable to resolve the fine structures present in the transport field (bottom right panel).
Projected climate change in transport (centre column, Fig. 13) is presented as a scalar field that is calculated as the change in the flow in the direction of transport of the control experiment (i.e. $(\Delta \boldsymbol{u} \cdot \boldsymbol{u}) /|\boldsymbol{u}|)$. Therefore, positive values represent an increase in transport in the direction of the control experiment. The projected climate change displays more fine-scale spatial structure due to mesoscale eddies in the FREE experiment, which is only a one-year average. In all experiments, in the region where the EAC flows as a single jet (latitudes 25 to $30^{\circ} \mathrm{S}$ ), there is a strengthening of the EAC. The experiments also give the suggestion of a southward shift in the point where a large component of the water turns east along the Tasman front. Also demonstrated is the high spatial variability of transport in the ODM, indicating the need for averages over a long time or large spatial domains to quantify results. Further analyses of boundary currents in downscaled projections around Australia are presented in Sun et al. (2012).

\section{Discussion and conclusions}

Ideally, we would like to increase the ocean resolution in a global coupled climate model, but the limited computational resources currently make such an approach unfeasible. We present here a framework to combine an AOGCM projection with an eddy-resolving ODM to downscale the effects of climate change on the marine environment. We integrate a high-resolution ODM with forcing fields computed by adding climate change anomalies in the heat, freshwater and momentum air-sea fluxes from the AOGCM to the presentday (1990s) forcing fields.

In our main projection (RELX), we restore the ODM's SST and SSS fields to monthly guide fields constructed by adding the SST and SSS climate change anomalies from the AOGCM to the present-day SST and SSS fields. The effective heat feedback coefficient in $\operatorname{RELX}\left(-16 \mathrm{Wm}^{-2} \mathrm{~K}^{-1}\right)$ is close to observed values (Frankignoul et al., 1998), and the salinity feedback is useful for stability and keeping the projected changes close to those from the AOGCM. An extended integration of the RELX projection is used to assess temporal stability of the ODM results. SST fields rapidly adjust in the first years and a consistent pattern emerges. After $\sim 5 \mathrm{yr}$ SST fields stabilise and year-to-year differences converge. A time series of EAC transport shows no trend or drift in circulation. The extended simulation is suitable for studies such as analysis of projected mesoscale dynamics (for example, Sun et al., 2012), marine impact analyses that benefit from the high resolution (Stock et al., 2011), or impact studies that explicitly require mesoscale properties like eddy-kinetic energy (Dell et al., 2011).

Two additional experiments explored the sensitivity of ODM projections to feedback parameterisations of ocean changes on air-sea fluxes. One experiment was run with no feedback (FREE). For another experiment (STRS), we use 
atmosphere-only simulations to estimate a correction to apply to the surface wind stress. To analyse the ODM climate results, we focus on differences such as the difference between the ODM climate projection and the ODM control experiment to reduce effects of model bias. We examine the differences in climate change in SST, SSS, upper ocean stratification and transports. From the three ODM projections, persistent patterns emerge in the differences in climate change between the ODM and AOGCM. The magnitude of differences in SST change is $\sim 0.5^{\circ} \mathrm{C}$ and in SSS change $\sim 0.1$ psu between the ODM and AOGCM projections. ODM projections persistently show greater warming in the Southern Ocean and northwest of Australia, and less warming in the Great Australia Bight and east of Tasmania. In SSS, the ODM projections are fresher at the mid-latitudes west of Australia and are generally saltier in the tropics and Southern Ocean. For vertical stratification the differences in climate change generally mirror the SSS differences. In places where the ODM is saltier in the Pacific, the ODM is also less stratified; likewise regions that are fresher in the ODM west of Australia show more stratification. The consistency of volume transport in the ODM projections is demonstrated by the strengthening and similar spatial response of the EAC in each ODM experiment.

The persistent and robust differences in climate change between the AOGCM and ODM projections demonstrate that resolving important boundary currents and eddies does alter the ocean response to climate change, independent of any feedback. However, the amplitude of the differences varies between experiments, indicating the projection is also sensitive to feedback. While a realistic heat feedback coefficient was applied in experiments here, the implementation was relatively simple as the coefficent was constant in space and time. Possible improvements include: using the state of an atmosphere and bulk formulas to improve the feedback on heat flux, or coupling with an atmosphere model to improve heat and stress feedback. However, these options would require further consideration to minimise effects of model bias in the projections.

The downscaling approach presented here provides an attractive way to explore marine impacts of climate change on regional and local scales, in particular in those regions where resolving eddies and boundary currents is critical for producing more realistic projections.

Acknowledgements. The ODM simulation was run at the High Performance Computing and Communications Centre and Australian National Computational Infrastructure (NCI) supercomputing facility. The FERRET program was used for analysis and graphics (http://ferret.pmel.noaa.gov/Ferret/). This work is supported by the WAMSI Node 2 project and with additional support from the Australian Climate Change Science Program and CSIRO Wealth from Oceans Flagship.

Edited by: R. Marsh

\section{References}

Ådlandsvik, B.: Marine downscaling of a future climate scenario for the North Sea, Tellus A, 60, 451-458, doi:10.1111/j.16000870.2008.00311.x, 2008.

Behrenfeld, M. J., O’Malley, R. T., Siegel, D. A., McClain, C. R., Sarmiento, J. L., Feldman, G. C., Milligan, A. J., Falkowski, P. G., Letelier, R. M., and Boss, E. S.: Climate-driven trends in contemporary ocean productivity, Nature, 444, 752755, doi:10.1038/nature05317, 2006.

Brassington, G. B., Pugh, T., Spillman, C., Schulz, E., Beggs, H., Schiller, A., and Oke, P. R.: BLUElink - development of operational oceanography and servicing in Australia, J. Res. Pract. Inf. Tech., 39, 151-164, 2007.

Cai, W. and Godfrey, S. J.: Surface heat flux parameterizations and the variability of thermohaline circulation, J. Geophys. Res., 100, 10679-10692, doi:10.1029/95JC00587, 1995.

Caputi, N., Chubb, C., Melville-Smith, R., Pearce, A., and Griffin, D.: Review of relationships between life history stages of the western rock lobster, Panulirus cygnus, in Western Australia, Fish. Res., 65, 47-61, 2003.

Caputi, N., Melville-Smith, R., de Lestang, S., Pearce, A., and Feng, M.: The effect of climate change on the western rock lobster (Panulirus cygnus) fishery of Western Australia, Can. J. Fish. Aquat. Sci., 67, 85-96, doi:10.1139/F09-167, 2010.

Cresswell, G. and Golding, T. G.: Observations of a south-flowing current in the Southeastern Indian Ocean, Deep-Sea Res. Pt. I, 27, 449-466, doi:10.1016/0198-0149(80)90055-2, 1980.

Dell, J., Wilcox, C., and Hobday, A., J.: Estimation of yellowfin tuna (Thunnus albacares) habitat in waters adjacent to Australia's East Coast: making the most of commercial catch data, Fish. Oceanogr., 20,383-396, doi:10.1111/j.1365-2419.2011.00591.x, 2011.

Dietze, H., Matear, R., and Moore, T.: Nutrient supply to anticyclonic meso-scale eddies off Western Australia estimated with artificial tracers released in a circulation model, Deep-Sea Res. Pt. I, 56, 1440-1448, doi:10.1016/j.dsr.2009.04.012, 2009.

Feng, M., Meyers, G., Pearce, A., and Wijffels, S.: Annual and interannual variations of the Leeuwin Current at $32^{\circ} \mathrm{S}$, J. Geophys. Res.-Oceans, 108, 3355, doi:10.1029/2002JC001763, 2003.

Frankignoul, C., Czaja, A., and L'Heveder, B.: Air-sea feedback in the North Atlantic and surface boundary conditions for ocean models, J. Climate, 11, 2310-2324, doi:10.1175/15200442(1998)011<2310:ASFITN>2.0.CO;2, 1998.

Gordon, H. B., Rotstayn, L. D., McGregor, J. L., Dix, M. R., Kowalczyk, E. A., O'Farrell, S. P., Waterman, L. J., Hirst, A. C., Wilson, S. G., Collier, M. A., Watterson, I. G., and Elliott, T. I.: The CSIRO Mk3 Climate System Model, CSIRO Atmospheric Research Technical Paper, 60, available at: http://www.cmar.csiro. au/e-print/open/gordon_2002a.pdf, 2002.

Gordon, H. B., O'Farrell, S. P., Collier, M. A., Dix, M. R., Rotstayn, L. D., Kowalczyk, E. A., Hirst, A. C., and Watterson, I. G.: The CSIRO Mk3.5 Climate Model, CAWCR Technical Report, 21, available at: http://www.cawcr.gov.au/publications/ technicalreports/CTR_021.pdf, 2010.

Griffies, S. M., Harrison, M. J., Pacanowski, R. C., and Rosati, A.: Technical Guide to MOM4, GFDL Ocean Group Technical Report No. 5, NOAA/Geophysical Fluid Dynamics Laboratory, available at: http://www.gfdl.noaa.gov/fms, 2004. 
Hartog, J. R., Hobday, A. J., Matear, R., and Feng, M.: Habitat overlap between southern bluefin tuna and yellowfin tuna in the east coast longline fishery - implications for present and future spatial management, Deep-Sea Res. Pt. II, 58, 746-752, doi:10.1016/j.dsr2.2010.06.005, 2011.

Heyen, H., Zorita, E., and von Storch, H.: Statistical downscaling of monthly mean North Atlantic air-pressure to sea level anomalies in the Baltic Sea, Tellus Series A, 48, 312-323, doi:10.1034/j.1600-0870.1996.t01-1-00008.x, 1996.

Hill, K. L., Rintoul, S. R., Coleman, R., and Ridgway, K. R.: Wind forced low frequency variability of the East Australia Current, Geophys. Res. Lett., 35, L8602, doi:10.1029/2007GL032912, 2008

Hobday, A., Poloczanska, E. S., and Matear, R. J.: Implications of Climate Change for Australian Fisheries: preliminary assessment., Report to the Department of Climate Change, Canberra, Australia, 2008.

Hobday, A. J. and Lough, J. M.: Projected climate change in Australia marine and freshwater environments, Mar. Freshwater Res., 62, 1000-1014, doi:10.1071/MF10302, 2011.

Kirtman, B. P., Fan, Y., and Schneider, E. K.: The COLA global coupled and anomaly coupled ocean-atmosphere GCM, J. Climate, 15, 2301-2320, doi:10.1175/15200442(2002)015<2301:TCGCAA > 2.0.CO;2, 2002.

Koslow, J. A., Pesant, S., Feng, M., Pearce, A., Fearns, P., Moore, T., Matear, R., and Waite, A.: The effect of the Leeuwin Current on phytoplankton biomass and production off Southwestern Australia, J. Geophys. Res.-Oceans, 113, C07050, doi:10.1029/2007JC004102, 2008.

Laprise, R., de Elía, R., Caya, D., Biner, S., Lucas-Picher, P., Diaconescu, E., Leduc, M., Alexandru, A., and Separovic, L.: Challenging some tenets of Regional Climate Modelling, Meteorol. Atmos. Phys., 100, 3-22, doi:10.1007/s00703-008-0292-9, 2008.

Large, W. B.: Surface fluxes for practioners of global data assimilation, in: Ocean Weather Forecasting: an Intergrated View of Oceanography, edited by: Chassinget, E. P. and Verron, J. A., Springer, Dordrecht, 229-270, 2005.

Levitus, S. (Ed.): World Ocean Database 2001, NOAA/NODC, Silver Springs, MD, USA, 2002.

Lo, J. C.-F., Yang, Z.-L., and Pielke, R. A.: Assessment of three dynamical climate downscaling methods using the Weather Research and Forecasting (WRF) model, J. Geophys. Res.-Atmos., 113, D09 112, doi:10.1029/2007JD009216, 2008.

Meier, H. E. M.: Baltic Sea climate in the late twenty-first century: a dynamical downscaling approach using two global models and two emission scenarios, Clim. Dynam., 27, 39-68, doi:10.1007/s00382-006-0124-x, 2006.

Mongin, M., Matear, R. J., and Chamberlain, M. A.: Simulation of chlorophyll and iron supplies in the Sub Antarctic Zone South of Australia, Deep-Sea Res. Pt. II, 58, 2126-2134, doi:10.1016/j.dsr2.2011.06.001, 2011.

Moore, T. M., Matear, R. J., Marra, J., and Clementson, L.: Phytoplankton variability off the Western Australian Coast: mesoscale eddies and their role in cross-shelf exchange, Deep-Sea Res. Pt. II, 54, 943-960, 2007.

Nakicenovic, N., Alcamo, J., Davis, G., de Vries, B., Fenhann, J., Gaffin, S., Gregory, K., Grübler, A., Jung, T. Y., Kram, T., Rovere, E. L. L., Michaelis, L., Mori, S., Morita, T., Pepper, W.,
Pitcher, H., Price, L., Riahi, K., Roehrl, A., Rogner, H.-H., Sankovski, A., Schlesinger, M., Shukla, P., Smith, S., Swart, R., van Rooijen, S., Victor, N., and Dadi, Z., eds.: Special Report on Emissions Scenarios: A Special Report of Working Group III of the Intergovernmental Panel on Climate Change, Cambridge University Press, Cambridge, UK, available at: http://www.grida. no/climate/ipcc/emission/index.htm, 2000.

Oke, P. R. and Griffin, D. A.: The cold-core eddy and strong upwelling off the coast of New South Wales in early 2007, DeepSea Res. Pt. II, 58, 574-591, doi:10.1016/j.dsr2.2010.06.006, 2011.

Oke, P. R., Schiller, G. B., Griffin, D. A., A., and Brassington: Ensemble data assimilation for an eddy-resolving ocean model of the Australian region, Q. J. R. Meteorol. Soc., 131, 3301-3311, doi:10.1256/qj.05.95, 2005.

Oke, P. R., Brassington, G. B., Griffin, D. A., and Schiller, A.: The bluelink ocean data assimilation system (BODAS), Ocean Model., 21, 46-70, doi:10.1016/j.ocemod.2007.11.002, 2008.

Phipps, S. J., Rotstayn, L. D., Gordon, H. B., Roberts, J. L., Hirst, A. C., and Budd, W. F.: The CSIRO Mk3L climate system model version 1.0 - Part 1: Description and evaluation, Geosci. Model Dev., 4, 483-509, doi:10.5194/gmd-4-483-2011, 2011.

Poloczanska, E. S., Babcock, R. C., Butler, A., Hobday, A., Hoegh-Guldberg, O., Kunz, T. J., Matear, R. J., Milton, D. A., Okey, T. A., and Richardson, A. J.: Climate change and Australian marine life, Oceanogr. Mar. Biol., 45, 407-478, 2007.

Reynolds, R. W. and Smith, T. M.: Improved global sea-surface temperature analyses using optimum interpolation, J. Climate, 7, 929-948, 1994.

Ridgway, K. R. and Condie, S. A.: The 5500-km-long boundary flow off Western and Southern Australia, J. Geophys. Res.Oceans, 109, C04017, doi:10.1029/2003JC001921, 2004.

Ridgway, K. R. and Dunn, J. R.: Mesoscale structure of the mean East Australian current system and its relationship with topography, Progress Oceanogr., 56, 189-222, doi:10.1016/S00796611(03)00004-1, 2003.

Schiller, A., Ridgway, K. R., Steinberg, C. R., and Oke, P. R.: Dynamics of three anomalous SST events in the Coral Sea, Geophys. Res. Lett., 36, L06606, doi:10.1029/2008GL036997, 2009.

Solomon, S., Qin, D., Manning, M., Chen, Z., Marquis, M., Averyt, K., Tignor, M., and Miller, H. (Eds.): Climate Change 2007: The Physical Science Basis. Contribution of Working Group I to the Fourth Assessment Report of the Intergovernmental Panel on Climate Change, Cambridge University Press, Cambridge, UK and New York, NY, USA, 2007.

Stock, C. A., Alexander, M. A., Bond, N. A., Brander, K. M., Cheung, W. W. L., Curchitser, E. N., Delworth, T. L., Dunne, J. P., Griffies, S. M., Haltuch, M. A., Hare, J. A., Hollowed, A. B., Lehodey, P., Levin, S. A., Link, J. S., Rose, K. A., Rykaczewski, R. R., Sarmiento, J. L., Stouffer, R. J., Schwing, F. B., Vecchi, G. A., and Werner, F. E.: On the use of IPCC-class models to assess the impact of climate on living marine resources, Prog. Oceanogr., 88, 1-27, doi:10.1016/j.pocean.2010.09.001, 2011.

Sun, C., Feng, M., Matear, R. J., Chamberlain, M. A., Craig, P., Ridgway, K., and Schiller, A.: Marine downscaling of a future climate scenario for Australia boundary currents, J. Climate, 25, 2947-2962, doi:10.1175/JCLI-D-11-00159.1, 2012. 
Uppala, S. M., Kallberg, P. W., Simmons, A. J., Andrae, U., Da Costa Bechtold, V., Fiorino, M., Gibson, J. K., Haseler, J., Hernandez, A., Kelly, G. A., Li, X., Onogi, K., Saarinen, S., Sokka, N., Allan, R. P., Andersson, E., Arpe, K., Balmaseda, M. A., Beljaars, A. C. M., Van De Berg, L., Bidlot, J., Bormann, N., Caires, S., Chevallier, F., Dethof, A., Dragosavac, M., Fisher, M., Fuentes, M., Hagemann, S., Hûlm, E., Hoskins, B. J., Isaksen, L., Janssen, P. A. E. M., Jenne, R., McNally, A. P., Mahfouf, J.-F., Morcrette, J.J., Rayner, N. A., Saunders, R. W., Simon, P., Sterl, A., Trenberth, K. E., Untch, A., Vasiljevic, D., Viterbo, P., and Woollen, J.: The ERA-40 re-analysis, Q. J. R. Meteorol. Soc., 131, 2961-3012, doi:10.1256/qj.04.176, 2005.
Wang, Y., Leung, L. R., McGregor, J. L., Lee, D.-K., Wang, W.-C., Ding, Y., and Kimura, F.: Regional climate modeling: progress, challenges, and prospects, J. Meteorol. Soc. Jpn., 82, 1599-1628, doi:10.2151/jmsj.82.1599, 2004.

Weaver, A. J., Marotzke, J., Cummins, P. F and Sarachik, E. S.: Stability and variability of the thermohaline circulation, J. Phys. Oceanogr., 23, 39-60, doi:10.1175/15200485(1993)023<0039:SAVOTT>2.0.CO;2, 1993.

Zhang, S., Lin, C. A., and Greatbatch, R. J.: A reexamination of the polar halocline catastrophe and implications for coupled ocean-atmosphere modeling, J. Phys. Oceanogr., 23, 287-299, doi:10.1175/1520-0485(1993)023<0287:AROTPH > 2.0.CO;2, 1993. 